\title{
The Study of New Media Art Aesthetic
}

\author{
You Guo \\ The Internatiaonal School \\ Huanghe Science and Technology College \\ Zhengzhou, China \\ e-mail: 5778459@qq.com
}

\author{
Daoxun Wang \\ The Internatiaonal School \\ Huanghe Science and Technology College \\ Zhengzhou, China \\ e-mail: frankwdx@126.com
}

\author{
Wenjun Cui \\ The Internatiaonal School \\ Huanghe Science and Technology College \\ Zhengzhou, China \\ e-mail: 592504682@qq.com
}

\begin{abstract}
Compared with traditional art, the aesthetic experience of new media art is characterized by diversification, interactivity, virtuality, etc. New media art not only drives but also influences the development of modern art. New media art implements the integration of mass culture and postmodern culture, promotes the process of virtualization development of future art and leads to the changes of aesthetic theory and aesthetic practice. In brief, new media art aesthetic exceeds the aesthetic view of traditional art. Instead of decomposing art, it makes use of the advantages of itself to improve the aesthetic value of art.
\end{abstract}

Keywords-new media art aestheti; experience property; decomposing; promote

\section{INTRODUCTION}

New media art, which is an art expression by means of techniques, develops rapidly in 21 st century which is also called digital era. It changes humans' lifestyle and aesthetic understanding of art. Now, new media art has become an important form of modern art which reflects new aesthetic characteristic to which traditional art cannot be compared. New media art aesthetic cannot be apart from media technology. To discuss new media art in terms of form of expression is not technology but art form developing from technology while the difference only lies in the bearing and transmission media. At the same time, new media art aesthetic comes into being because the aesthetic subject, object and environment make the corresponding changes. The spreading of a kind of cultural thoughts must first experience conflicts and then the process of integration.

\section{APPEARANCE OF NEW MEDIA ART AESTHETIC}

"Although influenced by the genetic factors in the psychological mechanism, aesthetic views of individuals are mainly acquired by the awakening and edification of the environment." The permeation and supporting of techniques and information spreading functions to the aesthetic psychological environment exist all the time in the traditional art aesthetic activities. Digitization is the core technique of the appearance and development of new art aesthetic views. Its characteristic, virtual reality, breaks the limitation of space and time and then reflects the situational atmosphere which people can or cannot imagine. The support of technical environment, the impact of spreading environment and the conflict and integration in cultural environment consist of the environment where new media art aesthetic appears and affect human's aesthetic views.

\section{A. Technical support "the bandwidth of performance"}

The artistic image of traditional art aesthetic activities is the materialistic virtual presentation which includes heterogeneity. For example, vocal music is delivered by throat; instrumental music is delivered by instruments; dance is delivered by dancers, etc. "Homogeneity results the uniqueness of information channel and terminal while the contradiction between relative finiteness of data statistic and delivery, reality and the infiniteness of the requirement of artistic performance results 'the bandwidth of performance'." In new media art, non-existent things can be created at random by humans' intuition and imagination by means of blending and generating the techniques. The digital presentation of new media art images has the characteristics of homogeneity that is to generate and delivery information by the data of sounds, images, human bodies, light and temperature. These characteristics break the traditional aesthetic principles and form virtual aesthetic categories. Whether aesthetic sense or objects come into being earlier than the other, aesthetic sense will drive the objects to obtain aesthetic value.

\section{B. Great impact in transmission "communication effect"}

In traditional art aesthetic activities, the receivers are in passive positions and can only be spiritually attracted to the subjects of creation by limited media information. They experience the true meaning of life by the overall views of beauty of humans. At the same time, the subjects of creation can meet with the aesthetic needs of publics only by means of using limited sources. But new media art is in a two-way communication which makes the aesthetic subjects become 
both creators and receivers so that they can acquire aesthetic experience of creation and recreation. Communication effect plays an important role in the transmission of new media art. In a word, it changes the traditional aesthetic environment of human being and creates a new aesthetic environmental pattern.

\section{Strike and integration in culture "memory of identity"}

In the history of the formation of aesthetic awareness, social development path, multi-ethnic culture integration and the way of regarding and inheriting the heritage all have important meaning. In traditional art aesthetic activities, the unity and finiteness of time and space lead to the accessibility of cultural identity in art aesthetic. Then aesthetic sense gradually becomes united. With the development of public media, the cultural differences of art appear. But because of the closure of traditional art, these cultural differences cannot be reflected clearly and can only be seen in static works. New media art breaks these obstacles and makes the spreading range wider, real-time interactive stronger and obtain interculturality. The dynamic openness in new media art may enlarge the cultural differences. There must be some conflicts among cultures in different countries but everybody has his cultural identity which is one's own cultural ascription that is edified by the environment through a long time and cannot be changed easily. So everybody will be shocked in the face of heterogenous culture.

\section{EXPERIENCE PROPERTIES OF NEW MEDIA ART}

"Beauty of technology exists widely in the field of science and technology which is formed from the blending of modern science and technology and art. It is also the product of modern science and technology and aesthetic activities." It is different from traditional art aesthetic that aesthetic activities, processes and properties of new media art can be a special entirety below different forms of new media art which can be presented perfectly.

\section{A. Multidimensionality of new media art aesthetic experiencing methods}

New media art aesthetic experiencing methods are multidimensional and rich. New media art not only integrates various media, builds new art forms by interacting with media but also makes use of the sufficient high-tech experience to realize the interaction between technology and art. It affects audiences' aesthetic experience and feelings.

\section{B. Interactivity in the process of new media art aesthetic experience}

The artistic value of new media art works is created by both artists and consumers. A good artistic work changes its aesthetic image and furthers its theme by thousands of individuals who internalize the work. The creation process ends until the work reaches a consensus when the audiences and artists communicate with each other. In this process, both the artists and the consumers have their own aesthetic understanding and inspiration and then enrich their aesthetic experience and improve their aesthetic ability.
C. Virtuality in the environment of new media art aesthetic experience

New media art is different from traditional art in the ways of existence and forms. It gets rid of the reliance of materials and forms an immaterial state measured by time which owns its special aesthetic situation.

\section{THE INFLUENCES OF NEW MEDIA ART ON MODERN ART AESTHETIC}

New media art is one of the most leading art forms, which is the result of artists devoting themselves into digital techniques and times. The expression of new media art is not only technical reformation but more likely an artistic feast. On the basis of the most important philosophy of artists' (Heidegger, Boyce and Benjamin) aesthetic and philosophical theories in 20th century, the illustration of the influences of new media art on modern art aesthetic is better for us to understand the aesthetic characteristics of new media art and appreciate the beauty with better aesthetic vision. It also provides reference significance and aesthetic theoretical basis for the future development of new media art.

\section{A. Decomposing of new media art to elite art}

In the 1950s, German ideologist Martin Heidegger foreseeingly claimed that human beings would enter an image era. Now people live in a postmodern society which is full of digital media. Human life is proceeding cultural invasion. This process is widely copied, flattened, generalized and modelled with the carrier which is digital media. The production of mass culture becomes mechanized assembly line work and a part of the system of production and consumption in the society. Elite art is unconsciously decomposed by the mass culture.

Decomposing of artistic charm: Walter Benjamin is a mavericks person in the school of Frankfurt who has unique opinion on techniques and art. Benjanmin's aesthetic view undoubtly influences the artistic characteristics of new media art, i.e. replicability, popularity and technicality. At the same time, it exploits how to preseve the value of traditional art at the technical time in order to combine techniques and art perfectly. This is the problem to be solved in the future development of new media art.

Decomposing of aesthetic distance: Everybody is possible to become an artist. "Artist" is simply a social character. No matter what kind of artists, the reason why they gain fame is not only individual opportunities and talents but also their social status and level of education. Besides, that they also rely on the media communication which is provided for them is also an important reason why they become famous. When the era of new media comes, network media becomes popular media communication method which makes "everybody is possible to be an artist" come true. Without the name of artist and expensive media, a lot of dilettantes realize their dreams of becoming artists and they own their works and audiences.

Decomposing of spiritual depth: Decomposing and extinction are different concepts. New media art is created by the fashionable artists by using advanced techniques. The 
public obtains more rights of speech though new media artists emphasize their works are different from commercial culture and refuse to make new media art become commercial art. One important reason is that technology is developing rapidly and the electrical communication tools such as digital videos, computers, printers, etc. are more and more common. Then new media art becomes a kind of mass art which is inevetably decomposing elite art. But decomposing is not extinction. If elite art equals to mass culture, aesthetic is meaningless.

\section{B. Aesthetic reformation brought by new media art}

Aesthetic orientation becomes more popular: Digital media art, as a new artistic form, develops rapidly. It creates conditions for those who used to have few chances or be unable to work on artistic creation and enjoy the creation process. Thus, there appears a kind of generalization of culture and a trend of aesthetic being more popular in the society. The traditional art becomes more various including movies, TVs, advertisement, performance art, new media art, etc. And culture also has spread from the original specific area to the present realm of spirit and consciousness. The popularity of mass culture makes human's daily life full of beauty. And the popularity of digital media provides public culture and entertainment with abundant basis. when compared with traditional art and classical aesthetic views, it seems not so magificent. The comtemporary artistic works which gain strong communication capabilities and public acceptance account for a large proportion in new media network. This fully reflects the biggest aesthetic reformation brought by new media art and the way of expression becomes more democratic.

Diversification of aeshetic interests: New media art is not only the artistic form produced by the media society but also the product of post-modern society. The post-modern cultural trend began in the late 1950s which makes great influences on the western culture. Postmodern art is similar to mass culture to some degree. That is to say postmodern art provides artistic and aesthetic support for mass culture. The development of new media art conflicts the postmodern cultural art and aesthetic value. No matter what kind of artistic works, they cannot be seperated from new media. New media art influence not only the means and ways of postmodern art creation but also the postmodern artists' aesthetic sense and creative ideas.

\section{THE PROMOTION OF NEW MEDIA ART TO MODERN ART AESTHETIC}

\section{A. To stimulate the pursuit of new aesthetic experience}

Each kind of production of art form cannot be separated from the discovery and usage of media. Since 19th century when humans entered the digital time, network has begun interaction with different kinds of media gradually. It uses media as means of input, output devices or communicating contents. Then integrated media and any media come into being. Now with the development of media, the audiences seek for something new about aesthetic experience. And multimedia meets with the needs of audience's and artistic development.
Multimedia is the combination of different media. For example, television combines images and sounds; newspaper combines words with images. However, the present multimedia is usually based on digital techniques. Hypermedia, considered as a large change between old and new media, is the combination of multimedia and hypertext technology. New media art works can be seen everywhere from simple pictures to massive online games. Besides integrate media and data, hypermedia can transform from one kind of media to another and express the same thing in different ways. A number of artists begin to undertake new works in this way to realize the transformation between images and words, images and sounds, sounds and words.

\section{B. The appearance of new artistic existential form}

With the popularity of modern network, digital media art becomes very hot. Digital art, based on the internet, is a new artistic form to do artistic creation and communication. In the time of anymedia, video phone, teleconference, digital television, etc. become the most convenient method of communication and the compulsory way of living. In the society full of digital media, digital photography, digital video and computer post-production is not the patent for professionals. On the contrary, artists can create new works which is accordance with his own aesthetic ideal by using the new artistic forms.

In conclusion, new media, hypermedia and anymedia time are contradictory to some degree. In the high-tech society, the contradictions are not absolute but relative. The coming of anymedia time is a process of the development of a country. And art will become a part of media through continuous conflicts, progress, integration and recombination.

\section{REFERENCES}

11] Li Sida, The History of Digital Media Arts.[M]. Beijing, Tsinghua University Press, 2008.

[2] Wang Li, The Comprehensive Survey of New Media Art Developmen.[M]. Tongji University Press, 2009.

[3] Zhu Guangqian, The History of Western Aesthetic,[M]. Jiangsu Literature and Art Publishing House,2008..

[4] Zhang Wenhua, New Media Art: The Aesthetic from Inter-Subjectivity.[J]. Journal of Xiamen University( Arts\&Social Sciences), 2009(2).

[5] Sun Wen, Mi Gaofeng, New Media Art and Its Aesthetic.[J]. New West, 2010(14).

[6] Pao Yuanfu, The Aesthetic Language of New Media Art.[J]. Modern Audio-Video Arts, 2009(2).

[7] Liu Fang, New Media Art and Our Life.[J]. Activity, 2011(8) 